\title{
IP3_AMARELO: Cybernatural e coexistência entre a natureza e máquina
}

Artur Cabral é artista computacional mestre em Artes Visuais pela Universidade de Brasília, doutorando bolsista CAPES também na Universidade de Brasília. Atualmente faz parte da equipe do $\mathrm{Me}-$ dialab/UNB, onde em suas pesquisas explora a relação arte e a computação em por meio de interfaces e poéticas computacionais.<arturcabralreis@gmail.com > ORCID: 0000-0002-4190-3965
Resumo 0 presente artigo discorre sobre a investigação teórica e prática para o desenvolvimento da obra computacional emergente e auto-organizada IP3_AMARELO, expondo os pensamentos e conceitos os quais inspiraram sua concepção. O texto apresenta também reflexões fundamentadas no conceito de cybernatural proposto por Mitchell Whitelaw, o qual propõe-se explicitar a possibilidade de uma coexistência entre o maquínico e o biológico, considerando a díade natureza-artifício.

Palavras chave Cybernatural, Natureza-artifício, Arte computacional, IP3_AMARELO. 


\section{IP3_AMARELO: Cybernatural and coexistence between nature and machine}

Abstract This article discusses the theoretical and practical investigation for the development of the emerging and self-organized computational work IP3_AMARELO, exposing the thoughts and concepts which inspired its conception. The text also presents reflections based on the concept of cybernatural proposed by Mitchell Whitelaw, which proposes to explain the possibility of a coexistence between the machinery and the biological, considering the dyad nature-artifice.

Keywords Cybernatural, Nature-artifice, Computational art, IP3_AMARELO.

IP3_AMARELO: Cibernatural y convivencia entre naturaleza y máquina

Resumen En este artículo se analiza la investigación teórica y práctica para el desarrollo del trabajo computacional emergente y autoorganizado IP3_AMARELO, exponiendo los pensamientos y conceptos que inspiraron su concepción. El texto también presenta reflexiones basadas en el concepto de cibernatural propuesto por Mitchell Whitelaw, que propone explicar la posibilidad de una convivencia entre la maquinaria y lo biológico, considerando la díada naturaleza-artificio.

Palabras clave Cybernatural, Naturaleza-artificio, Arte computacional, IP3_AMARELO. 


\section{Introdução}

A arte relacionada à computação, principalmente na década de 1980 até meados de 1990, procurou transformar sistemas maquínicos e regrados em sistemas com características orgânicas, criando tecnologias que assumem aparências "biológicas", valendo-se desse aspecto natural mediante um índice direto da natureza, de caráter simbólico, baseado nas experiências mais básicas e pessoais com a natureza, reproduzindo árvores e folhagens, por exemplo, ou seres de aparência zoomórfica, e em alguns casos, apresentando o processo construtivo desses agentes virtuais (WHITELAW, 2004).

A analogia biológica destes primeiros trabalhos artísticos, principalmente com vida artificial, concentrava-se nos aspectos de representação da evolução e abordava temas como emergência e criatividade, sem críticas em relação à tecnologia ou à nossa relação com o meio circundante natural. Mas, simultaneamente, surgia uma forma de crítica que provocou tensão entre intelectuais e artistas, em função do que ocorria entre o ambiente natural e o contexto informacional, chamando a atenção para emaranhamento ou separação de um exterior natural e um interior computacional. Essa tensão que encobre os aspectos da dualidade do feito e do nascido, da computação e da vida, natureza e artifício, é denominado pelo pesquisador Mitchell Whitelaw de cybernatural. A grande contribuição desses trabalhos computacionais atuantes no contexto do cybernatural é, justamente, a explicitação, ainda que não intencional, da divisão ordenada do "binário" natureza e tecnologia, que é "desbinarizado", fundido e transposto, tornando natureza e tecnologia substancialmente indistinguíveis.

A "desbinarização" não ocorre pelo fato do artifício simbólico das obras estarem progressivamente mais semelhantes ao objeto referente no mundo natural, entretanto, se dá na constituição desse artifício, na sua estrutura gerativa.

Os primeiros trabalhos artísticos no campo da vida artificial, de circulação internacional, entendidos nesse período como natureza artificial, tendo como exemplo as obras de Sommerer e Mignonneau ou de Miguel Chevalier, possuíam uma preocupação significativa com a interatividade, pois é a partir da interatividade que esses trabalhos adquirem um engajamento especial. Em síntese, a interatividade humano-máquina é algo central em uma série de trabalhos significativos na história da arte computacional. 


\section{A Obra IP3_AMARELO e a Noção de Natureza}

A ideia de conceber obras que tensionam a relação dos humanos com as máquinas e com a chamada "natureza", de certa forma evidencia a inestimável agência de ambas, nos distanciando, enquanto artistas, da preocupação com a construção de ambientes artificiais interativos complexos, a fim de nos aproximarmos da tentativa de prestar atenção e interrogar o que estes ambientes omitem ou implicam.

Dessa forma, desenvolvemos no MediaLab/UnB ${ }^{1}$ a criação de uma obra computacional na qual a interatividade acontece através das relações internas da máquina. Tendo em vista que a obra se fundamenta em algoritmos evolutivos e na mimética de vidas naturais, atribuímos ao computador a função de manter e conduzir esta vida computacional, que a cada execução apresenta-se de forma diferente. Neste projeto elegemos a árvores para representar a natureza, a adaptação da forma de vida simulada através dos processos computacionais define a IP3_AMARELO (2018) como ser vivo, por meio da sua capacidade de se auto-organizar. Para nós, este fenômeno biológico simulado por meio de algoritmos computacionais estabelece também um diálogo entre o ambiente "natural" e sua simulação.

Um evento importante que consideramos nesta obra é o fator tempo, que cria uma outra oportunidade de experimentação na perspectiva artística mediada na relação natureza-máquina, uma vez que o tempo de evolução dessa vida computacional diferencia-se do tempo de crescimento da vida natural, bem como do tempo dos fenômenos tecnológicos, os quais aceleram a cada dia, considerando que a simulação da árvore apresenta um ciclo evolucionário circadiano, ou seja, nasce e morre em um período de 24 horas.

Contudo, em um processo de autocrítica a respeito deste trabalho, percebemos que mesmo suprimindo a interatividade humana no momento de apreciação desta obra interativa, esse sistema ainda evoca uma analogia demasiada literal entre estruturas biológicas e computacionais, reforçando uma noção antropocêntrica da natureza, como conseqüência de suas formas representacionais. Estas questões nos perturbam e nos surpreendem. Somos atormentado pelo surgimento de perguntas como: Se a computação pode reproduzir a natureza, o que acontece com seu original biológico? E se, em vez de procurar reproduzir formas naturais familiares, esses sistemas computacionais fossem abordados em seus próprios termos? Como se posicionam contra o binário cibernético natureza-artifício?

Sendo assim, buscamos ir contra a ideia de pensar a ação humana

Fig 1. Frame obra IP3_AMARELO (2018). Exposta na Artis Intelligentia: Imaginar o Real - Museu de Belas Artes, Porto, Portugal

Fonte: Autor, 2018
- por consequência, a construção de objetos - como algo antagônico à natureza ou como um instrumento de domesticação da natureza. 0 pensamento do antropólogo Bruno Latour, se torna indispensável para entendermos esta noção, por sua vez, considera que a criação humana de artífices são inerente à natureza, estendendo-se também para a manipulação genética, construção de cidades, criação de vidas artificiais computacionais, reflorestamentos, os quais são simultaneamente naturais e artificiais, ou melhor, são sobrepostos pelas múltiplas naturalidades (LATOUR, 2014).

DATJournal v. 6 n. 12021 
A arte tem um papel preponderante nessas discussões, pois contribui com uma nova forma de entender o mundo, na medida em que dialoga de forma intensa como a humanidade, manipulando, transformando e reproduzindo a natureza, além de propor um diálogo impetuoso referente a como tudo isso tem afetado nossa noção de natural.

Um outro trabalho interessante para pensar estas circunstâncias, que tenciona esse conceito de naturalidade, é a obra transgênica OneTrees (2000-2004) idealizada pela artista Natalie Jeremijenko. Nesse projeto a artista clonou 100 árvores como uma maneira de expressar a complexa interação da genética com a influência dos múltiplos agentes ambientais, que, segundo a artista, muitas vezes é simplificada no discurso público sobre clonagem. Clones das árvores são plantados em locais públicos na baía de São Francisco por serem geneticamente equivalentes. Espera-se que possuam aspectos visuais e sistemáticos idênticos, porém, à medida que se desenvolvem expressam as diferenças ambientais e as ações dos agentes aos quais estão expostos, dando origem a árvores singulares. De forma simbólica, a artista explicita algo que de outra forma não seria visível para um público não científico, e cria uma forte tensão entre os aspectos e as ações considerados naturais e os considerados artificiais, e como eles se relacionam e criam emaranhados, o quais não podemos caracterizar como naturais ou artificiais.

Fig 2. Fotografia do projeto OneTrees Fonte: Site Deeproot $^{2}, 2010$

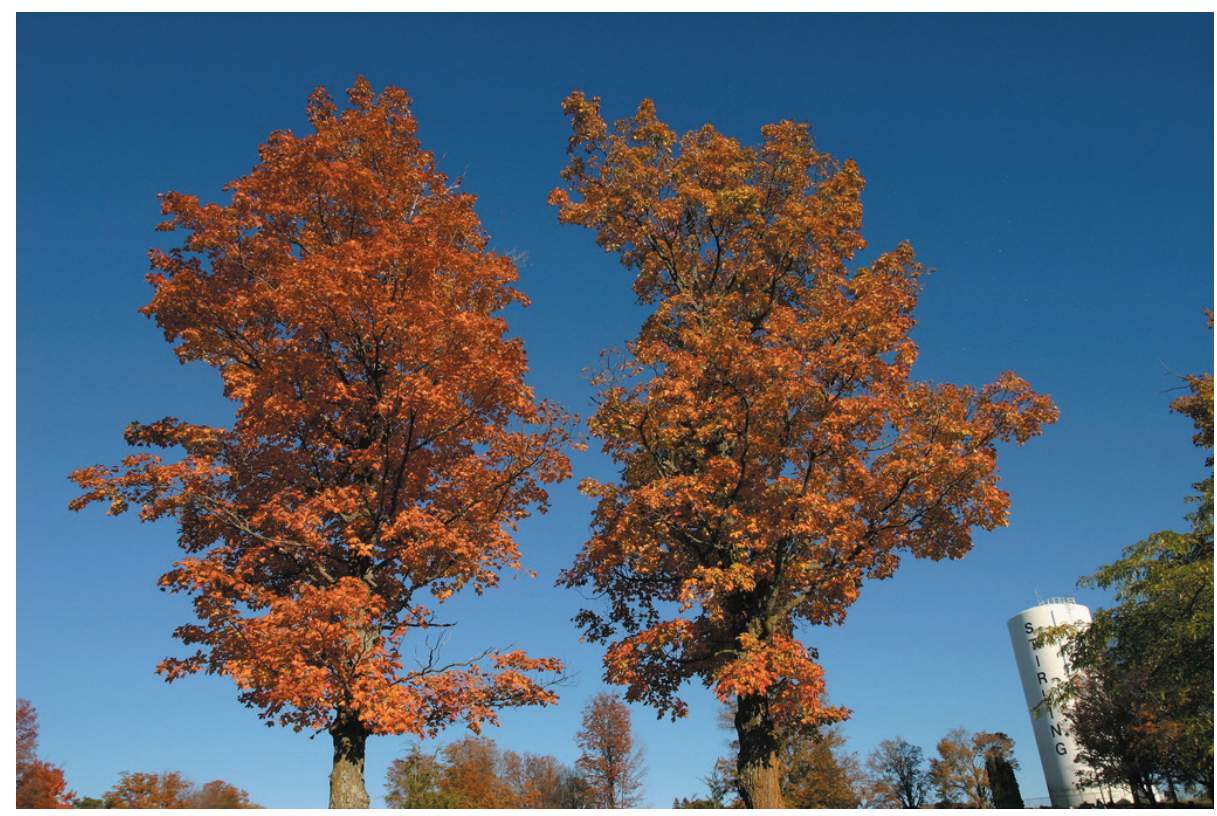

Consequentemente, podemos entender que a natureza não se opõe à cultura, se considerarmos o aquecimento global e o conceito de antropoceno. Porém, acreditamos ser necessário valorizar as suas relações e negociações, fomentando uma centralidade distribuída. 
A professora e pesquisadora Ursula Huws (2014) infere que, livres de correntes binárias, podemos então assumir um compromisso ético independente de uma hierarquia, com agenciamentos irrestritos entre objetos técnicos, humanos, animais, plantas, rochas etc. Para tanto, devemos pactuar o compromisso de aumentar as possibilidades dentro dessas relações, esvaindo-se das abstrações isoladas que nos acompanham há séculos e nos afastando dos estereótipos para repensar nosso agenciamento no mundo. Para a autora, a relação de três vias entre a natureza, a tecnologia e o humano, tem sido um assunto recorrente na contemporaneidade e está mudando a problemática da arte e de todo o pensamento ocidental. Huws nos convida a participar de um projeto que busca reinventar a relação entre tecnologia e natureza, que, segundo ela, está principalmente nas mãos dos artistas. Visto que enquanto artistas podemos agir como

\footnotetext{
...uma espécie de comentarista freelancer, fornecendo insights sobre o funcionamento do universo que vai além do literal, chamando nossa atenção para a ironia, o pathos, a beleza ou a extraordinária natureza do mundo em que habitamos. E aos impressionantes poderes para destruí-lo ou transformá-lo, que estão nas mãos dos cientistas. (HUWS, 2014, p. 40, tradução nossa).
}

\section{Considerações Finais}

No contexto da discussão a respeito da díade entre artifício e natureza, precisamos avaliar de forma crítica a cultura ocidental, em especial a tentativa de criar uma dualidade entre natureza e cultura. Por conseguinte, nossa produção artística, em especial o trabalho IP3_AMARELO busca revelar, também, como artistas podem ser cúmplices na construção do cybernatural não antropocêntrico, para expandir nossa consciência de sistemas biológicos que é o avesso do sistema binário: natural e artificial. Desta forma, acreditamos que dispondo da presença da natureza nos sistemas tecnológicos e informacionais, podemos alterar ou contestar as noções e convicções a respeito da nossa relação com toda a biosfera.

Isto é, considerando que poucos cientistas têm a liberdade de sair das suas prisões disciplinares para apresentar uma visão integrativa acessível a um público leigo. Assim sendo, neste projeto, para entender a relação entre a compressão do humano e do mundo natural, a arte torna-se uma ferramenta chave, produzindo um exercício necessário e urgente, de especular sobre as direções futuras das tecnologias e a nossa relação com o meio circundante. Deste modo, acreditamos que este é um dos papéis delegados aos artistas, além do papel de estimular uma reflexão e ceticismo moderado por meio da criação de novas narrativas e modelos, criando uma articulação entre todas as dimensões sociais de uma nova tecnologia, infiltrando-se em discussões e eventualmente agindo na realidade concreta. 
1 Participaram também do projeto Suzete Venturelli, Leandro Ramalho e Fernando Aguilar.

2 Disponível em <http://www.deeproot.com/blog/blog-entries/onetrees-the-forgotten-tree-art-project> . Acesso em 29 de dez. de 2019.

\section{Referências}

CABRAL, A., Venturelli, S., \& Prado, G. (2019). Signals detected between biological and machinic. DAT Journal, 4(3), 117-127. (https://doi.org/10.29147/dat.v4i3.152)

HUWS, Ursula Huws. Nature, Technology and Art: The Emergence of a New Relationship? Leonardo. Vol. 33, No. 1 (2014), pp. 33-40.

LATOUR, Bruno. Agency at the time of the anthropocene. New Literary History. Vol..45, n.1, p.1-18, 2014.

Natalie Jeremijenko «One Trees» . Medien Kunst Netz, 2012. Works. Disponível em: <http:// www.medienkunstnetz.de/works/one-trees/. Acesso em: 03, outubro de 2020.

Prado, G. Project Amoreiras (Mulberry Trees): Autonomy and Artificial Learning in an Urban Environment. Leonardo 2018 51:1, 61-62. The MIT Press (https://doi.org/10.1162/LEON_a_01557).

PRADO, Gilbertto. Grupo Poéticas Digitais: projetos desluz e amoreiras. ARS (São Paulo), São Paulo, v. 8, n. 16, 2010 . pp. 110-125. (https://doi.org/10.1590/S1678-53202010000200008). SANTAELLA, Lúcia. Game arte no contexto da arte digital. DAT Journal, v. 2, n. 1, p. 3-14, 14 out. 2017. (https://doi.org/10.29147/2526-1789.DAT.2017v2i1p2-13)

SOGABE, M., Peres, C., Fogliano, F., Nunes, F. O., Braz, S., Peres, C., \& Gazana, C.(2017). The Blow. DAT Journal, 2(1), 105-115. (https://doi.org/10.29147/2526-1789.DAT.2017v2i1p104-114)

VENTURELLI, S., Rocha, C., Augusto da Silva, T., Coutinho, C., Cabral Reis, A., Bartholo, C., Mutti, G., Balduíno, G., Ramalho, L., Luize Martins, T., \& Hargreaves, P. (2018). Poiesis of the body. DAT Journal, 3(1), 147-155. (https://doi.org/10.29147/dat.v3i1.78)

VENTURELLI, S., Witt, A., Reis, A. C., \& Loures, J. (2017). Gameart: Arte e conscientização ecológica. DAT Journal, 2(1), 44-54. (https://doi.org/10.29147/2526-1789.DAT.2017v2i1p43-53) VENTURELLI, Suzete. Arte: espaço_tempo_imagem. Brasília: Edunb, 2004.

WHITELAW, Mitchell. Metacreation - Art and Artificial Life. Cambridge, Mass.: The MIT Press, 2004. 